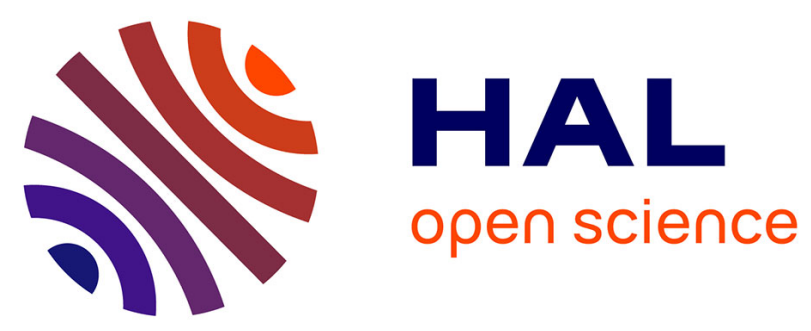

\title{
Numerical modeling of long-term earthquake sequences on the NE Japan megathrust: comparison with observations and implications for fault friction
}

Nadaya Cubas, Nadia Lapusta, Jean-Philippe Avouac, Hugo Perfettini

\section{To cite this version:}

Nadaya Cubas, Nadia Lapusta, Jean-Philippe Avouac, Hugo Perfettini. Numerical modeling of long-term earthquake sequences on the NE Japan megathrust: comparison with observations and implications for fault friction. Earth and Planetary Science Letters, 2015, pp.1-30. 10.1016/j.epsl.2015.03.002 . hal-01137698

\author{
HAL Id: hal-01137698 \\ https://hal.science/hal-01137698
}

Submitted on 31 Mar 2015

HAL is a multi-disciplinary open access archive for the deposit and dissemination of scientific research documents, whether they are published or not. The documents may come from teaching and research institutions in France or abroad, or from public or private research centers.
L'archive ouverte pluridisciplinaire HAL, est destinée au dépôt et à la diffusion de documents scientifiques de niveau recherche, publiés ou non, émanant des établissements d'enseignement et de recherche français ou étrangers, des laboratoires publics ou privés. 


\title{
Numerical modeling of long-term earthquake sequences on the NE Japan megathrust: comparison with observations and implications for fault friction
}

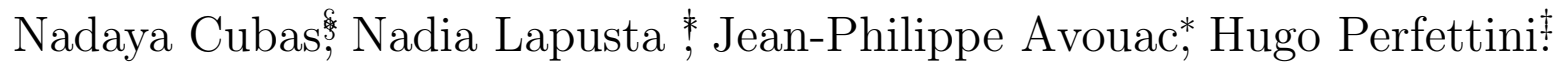

\begin{abstract}
We use numerical modeling to investigate fault properties that explain key features of the $2011 \mathrm{Mw} 9.0$ Tohoku-Oki earthquake as well as the overall regional behavior of the NE Japan Megathrust. In particular, we study the possibility that slip near the trench resulted from thermal pressurization on a shallow patch of the megathrust, and investigate whether low-velocity friction on that patch is ratestrengthening or rate-weakening. Our models also contain a deeper rate-weakening patch, not prone to efficient thermal pressurization, to account for the moderate-sized interplate seismicity. We produce earthquake sequences and aseismic slip in our models using $2 \mathrm{D}$ dynamic simulations that incorporate shear-induced temperature variations and the associated change in pore fluid pressure to capture thermal pressurization. We find that all our models can reproduce more frequent deeper moderate $(\mathrm{Mw}$ 7.5) events and less frequent larger events with substantial slip at shallow depth, as observed along the Fukushima-Miyagi segment of the Japan megathrust. However, only the scenario with a sufficiently rate-strengthening patch can match the
\end{abstract}

\footnotetext{
${ }^{1}$ Division of Geological and Planetary Sciences, California Institute of Technology, 1200 E. California Blvd, 91125 Pasadena, USA

${ }^{2}$ Division of Engineering and Applied Science, California Institute of Technology, 1200

E. California Blvd, Pasadena, CA 91125, USA

${ }^{3}$ Institut de Recherche pour le Développement, ISTerre, Grenoble, France

${ }^{4}$ Now at Institut des Sciences de la Terre, Université Pierre et Marie Curie, UMR 7193, 4 place Jussieu 75005 Paris, France
} 
thousand-year recurrence time of Tohoku-Oki-like earthquakes suggested by the historical and geological record, due to co-existence of seismic and aseismic slip at the shallow depths. This scenario also reproduces other characteristics of the Tohoku-Oki earthquake: the trenchward-skewed distribution of slip, the backward re-rupture of the deeper patch, as well as the weaker radiation at high frequency of the shallower portion of the rupture in spite of its larger slip.

\section{keyword}

Tohoku-Oki earthquake, Thermal pressurization, Shallow propagation 


\section{Introduction}

The 2011 Mw 9.0 Tohoku-Oki earthquake produced exceptionally large shallow slip, at depth between 10 and $20 \mathrm{~km}$, generating a major tsunami [Yamigawa et al., 2015; Bletery et al., 2014; Wei et al., 2012; Ozawa et al., 2011; Ide et al., 2011; Simons et al., 2011, Ito et al., 2011] (fig. 1a). The rupture propagated all the way to the trench, with the shallow-portion displacement of 15 to $40 \mathrm{~m}$ as attested from the displacement of ocean-bottom pressure gages [Ito et al., 2011] and comparison of bathymetric profiles measured in 1999 and after the earthquake in March 2011 [Fujiwara et al., 2011].

This large shallow slip is most surprising since (1) the upper portion of the megathrust is commonly thought to slip aseismically [e.g., Byrne et al, 1992; Oleskevich et al., 1999], (2) previous magnitude 7.5 earthquakes had only been instrumentally recorded along the deeper portion of the megathrust (fig. 1b), and (3) interseismic strain accumulation models were not showing any evidence for locking of the megathrust at shallow depth [Hashimoto et al., 2009; Loveless and Meade, 2011]. It should be noted, however, that the creep at shallow depth inferred from the interseismic models [Hashimoto et al., 2009; Loveless and Meade, 2011] was essentially due to the assumed initial condition and lack of resolution near the trench of the onshore geodetic data used in these inversions [Loveless and Meade, 2011].

Figure 1a shows the co-seismic and afterslip models of Yamagiwa et al. [2015] derived from the modelling of on-shore and seafloor displacements. The co-seismic model is similar to the models obtained by other groups incorporating seismological and tsunami waveforms [e.g., Bletery et al., 2014], which all show that the rupture propagated close to the trench. The deeper patch of afterslip outlines the downdip end of the co-seismic rupture as observed by previous studies [Ozawa et al., 2012; Johnson et al., 2012; Sun et al., 2014; Hu et al., 2014]. There is some degree of uncertainty regarding the exact amount of slip that occurred near the trench due to the fact that the postseismic seafloor measurements were acquired weeks after the mainshock. Eastward displacement and subsidence at station FUKU, south of the rupture area, clearly indicate shallow afterslip there. In contrast, the postseismic sea-floor displacements are mostly westward above the rupture area and indicate a predominantly viscoelastic relaxation process there, over the time period covered by these measurements, from one month to three years after the mainshock [Sun et al., 2014; Watanabe et al., 2014; Hu et al., 2014]. The data does not rule out the possibility of shallow afterslip but the 
afterslip would need to be small enough to be obscured by the viscoelastic response over this time period. As suggested by Perfettini and Avouac [2014] (see their section 6.3 and Appendix A1), some significant shallow afterslip could have occurred over the first month. The afterslip model of Yamagiwa et al. [2015] shows both deep and shallow afterslip mostly complementary to the co-seismic rupture area. It should be noted that this afterslip model, similarly to others [e.g., Ozawa et al., 2012], assumes no slip at the trench as a boundary condition in the inversion. Shallow afterslip could be underestimated as a result of this boundary condition and of the Laplacian regularization.

An interseismic coupling model before the Tohoku-Oki event is shown in Figure 1b. It is a revised version of the model given in Figure 11 of Perfettini and Avouac [2014]. In this revised version, the interseismic seafloor displacements of Matsumuto et al. [2008] were replaced by the more recent measurements of Sato et al. [2013]. These measurements, initially given relative to the North American plate, are referenced to NE Honshu assuming the NUVEL-1A plate motion of North America relative to Eurasia and the block motion of NE Honshu relative to Eurasia of Loveless and Meade [2011]. We have considered two boundary conditions: one for which back-slip is prohibited near the trench (corresponding to a creeping trench at the long term slip rate prior to the mainshock, dabbed CT in the following), and another one for which back-slip rate at the trench is unconstrained (corresponding to a partially to fully locked trench prior to the mainshock, dabbed LT in the following). The two resulting inverted models yield nearly identical coupling maps, with the corresponding reduced chi-square values being 9.82 and 9.76 , respectively; the LT model is shown in Figure 1b. The LT model matches the data slightly better than the CT model because it has more degrees of freedom. The comparison of observed and predicted displacements and residuals are shown in the supplementary material.

Therefore, the seafloor measurements as reported in Sato et al. [2013] require some amount of interseismic creep near the trench. This implies that the locked patches below are apparently not screening the interseismic loading as would be expected from the stress shadow effect [Bürgmann et al., 2005; Hetland and Simons, 2010]. Note that the historical ruptures are all located in the highly coupled area, with the exception of the 1896 Sanriku tsunami earthquake (Fig. 1b). It thus seems that the shallow portion of the Japan megathrust could creep aseismically, e.g. as afterslip and interseismically, as well as accumulate substantial slip during large tsunamigenic earthquakes. 

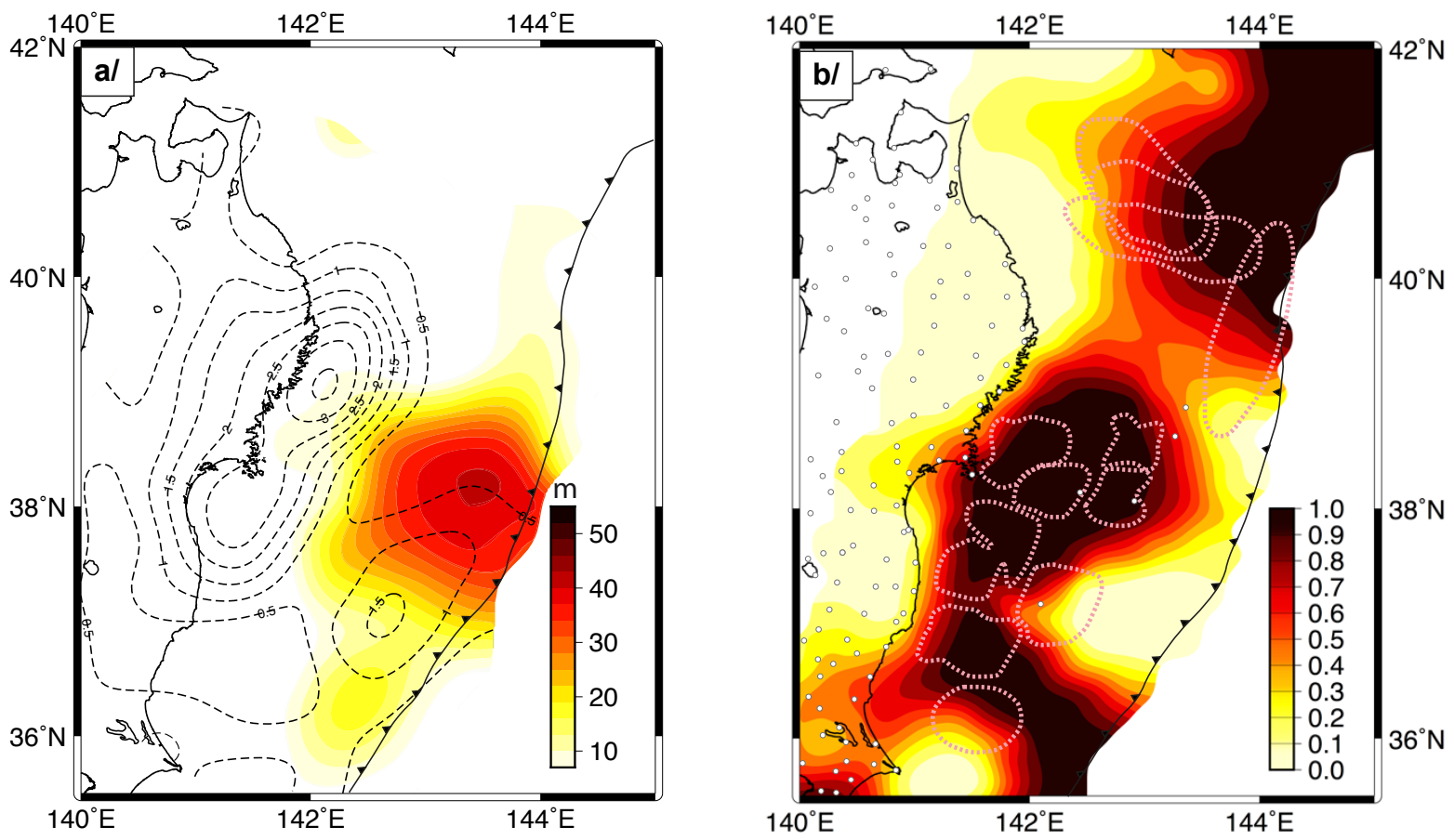

Figure 1: a) Coseismic (colors) and postseismic (black dashed lines) slip from Yamagiwa et al. [2015] derived from the modeling of on-shore and seafloor displacements. b) Interseismic coupling ratio (colors) from an updated inversion of onshore and offshore geodetic measurements based on Perfettini and Avouac [2014] but including the interseismic seafloor displacements of Sato et al. [2013]. Comparison of the observed and predicted displacements is given in the supplementary figure. The dotted pink contour lines show the estimated location of rupture areas of smaller $(\sim$ M7.5) historical earthquakes [Yamanaka and Kikuchi, 2004; Shibazaki et al., 2011; Johnson et al., 2012]. 
The Tohoku-Oki earthquake is remarkable in two other ways. The large shallow slip area did not radiate much seismic energy at high frequencies compared to the deeper portion of the megathrust which experienced less slip [Ide et al., 2011; Simons et al., 2011; Meng et al., 2011; Wei et al, 2012]. A complex propagation was also observed, with a small initial phase of deep rupture up to $40 \mathrm{~s}$, followed by extensive shallow rupture at $60-70 \mathrm{~s}$, and a continuing deep rupture lasting over 100 s [Ide et al., 2011]. Finally, from tsunami records [Sawai et al., 2012], the last earthquake in the area with comparable tsunami deposits occurred in AD 869 and hence the recurrence time of the Tohoku-Oki-like events is probably 1000 years, unless the recurrence interval is quite irregular.

To reconcile these observations, Noda and Lapusta [2013] have suggested that the shallow megathrust could undergo aseismic slip at low slip rates, due to its rate-strengthening properties, as well as substantial coseismic slip due to efficient weakening by thermal pressurization of pore fluids [Sibson, 1973; Lachenbruch, 1980; Mase and Smith, 1985, 1987; Rice, 2006]. From model parameters based on lab experiments [Tanikawa and Shimamoto, 2009], they were able to reproduce the larger slip of the shallow (rate-strengthening) patch, the difference of the frequency content of seismic radiation, and the re-rupture of the deeper (rate-weakening) patch. This dual behavior, ratestrengthening at low slip rates and strong weakening at seismic slip rates, was also observed from lab experiments on wet clays characteristic of shallow megathrust, and also attributed to thermal pressurization at high slip rates [Faulkner et al., 2011]. We also note that the post-earthquake temperature measurements in the shallow part of the megathrust imply a co-seismic friction coefficient of 0.08 [Fulton et al., 2013], which supports substantial co-seismic weakening during the Tohoku-Oki earthquake.

However, thermal pressurization can explain the large co-seismic slip regardless of the rate-strengthening or rate-weakening behavior of the shallow zone. Since it is uncertain that the megathrust was fully locked up to the trench before the Tohoku-Oki event [Loveless and Meade, 2011], the properties of the interface can be rate-weakening at low slip rates. This hypothesis has been considered in dynamic simulations, which attributed the large shallow slip to either enhanced weakening at high slip rate by strong slipweakening [Shibazaki et al., 2011], or thermal pressurization [Mitsu et al., 2012], or the effect of the free surface [Kozdon and Dunham, 2013].

Determining if the observed behavior of the megathrust that hosted the 2011 Tohoku-Oki event is due to an unusual rate-weakening shallow patch or 
to co-seismic weakening of an otherwise rate-strengthening shallow portion of the fault is of fundamental importance for future seismic and tsunamigenic risk assessment.

In this study, we follow up on the study of Noda and Lapusta [2013] and investigate several possible scenarios of the megathrust properties, some with a shallow rate-weakening patch and others with a shallow rate-strengthening patch. All models include a deeper seismogenic zone where magnitude $\sim 7.5$ earthquakes occur. In all scenarios, the shallow zones can undergo coseismic weakening by thermal pressurization. The model set-up and results are presented in the next two sections. To determine the most likely scenario, simulations results are compared to the observed slip accumulation of the last 300 years along the Fukushima-Miyagi segment. The approach is conceptually similar to the modeling of the Parkfield segment of the San Andreas Fault in Barbot et al. [2012] but under a two-dimensional approximation and incorporating the effect of thermal pressurization. Note that our models do not incorporate a free surface. The interaction of the earthquake-generated stress field with a free surface can promote large slip at shallow depth during thrust event [Oglesby et al., 1998] and this effect may have been at play

during the Tohoku-Oki earthquake [Kozdon and Dunham, 2013]. We take into account this discrepancy in our comparison.

\section{Dynamic simulation of fault slip}

\section{$2.1 \quad$ Model}

We use the 2D modeling approach of Noda and Lapusta [2010], which builds on earlier work by Lapusta et al. [2000] and Lapusta and Liu [2009]. The approach allows to simulate slow fault slip as well as self-driven rupture propagation with all inertial effects under slow tectonic-type loading in a mode II configuration while accounting for shear heating and pore pressure changes. Our model consists of a planar fault embedded in a homogeneous elastic medium and governed by the ageing form of the rate-and-state friction law [Dieterich, 1979; Rice and Ruina, 1983; Ruina, 1983]:

$$
\begin{gathered}
\tau=(\sigma-p)\left(\mu_{o}+a \ln \frac{V}{V_{o}}+b \ln \frac{V_{o} \theta}{L}\right), \\
\dot{\theta}=1-\frac{V \theta}{L}
\end{gathered}
$$


where $\sigma$ is the elastodynamic normal stress, $p$ is the pore pressure, $\sigma-$ $p=\sigma^{e f f}$ is the effective normal stress, $\mu_{o}$ and $V_{o}$ are the reference friction coefficient and slip rate, $V$ the slip rate, $a>0$ and $b>0$ are rate and state parameters, $\theta$ is a state variable which can be interpreted as the average age of the population of contacts between two surfaces, and $L$ is the characteristic slip for state evolution [e.g. Dieterich, 1979; Rice and Ruina, 1983; Ruina, 1983]. At constant slip rate, the shear stress $\tau$ evolves towards steady state:

$$
\tau_{s s}=(\sigma-p)\left(\mu_{o}+(a-b) \ln \frac{V}{V_{o}}\right) .
$$

If $a-b<0$, the friction is rate-weakening leading to a stick-slip behavior on large enough fault patches, whereas for $a-b>0$, the friction is rate-strengthening allowing for stable sliding. Note, however, that ratestrengthening areas can also be locked, for example, after they experience seismic slip that drops their shear stress levels [Noda and Lapusta, 2013].

To capture thermal pressurization leading to efficient coseismic weakening, the model incorporates shear-induced temperature variations on the fault and the associated evolution of pore fluid pressure, in the form [e.g., Lachenbruch, 1980]:

$$
\begin{gathered}
\frac{\delta T(x, y, z, t)}{\delta t}=\alpha_{t h} \frac{\delta^{2} T(x, y, z, t)}{\delta y^{2}}+\frac{\omega(x, y, z, t)}{\rho c} \\
\frac{\delta p(x, y, z, t)}{\delta t}=\alpha_{h y} \frac{\delta^{2} p(x, y, z, t)}{\delta y^{2}}+\Lambda \frac{\delta T(x, y, z, t)}{\delta t}
\end{gathered}
$$

where $T(x, y, z, t)$ is the temperature, $p(x, y, z, t)$ is the pore fluid pressure, $\omega(x, y, z, t)$ is the shear heating source, $\alpha_{t h}$ is the thermal diffusivity, $\alpha_{h y}$ is the hydraulic diffusivity, $\rho c$ is the specific heat capacity, and $\Lambda$ is the pore pressure change per unit temperature under undrained conditions. The shear heating source is due to fault slip:

$$
\omega=\tau V \frac{\exp \left(-y^{2} / 2 h_{w}^{2}\right)}{\sqrt{2 \pi} h_{w}}
$$

where $h_{w}$ is the half width of the shear zone.

\subsection{Model set-up}

Based on coseismic slip and afterslip models of the Tohoku-Oki earthquake [Wei et al., 2012; Perfettini and Avouac, 2014; Bletery et al., 2014; Yam- 
agiwa et al., 2015] as well as on the rupture areas of previous more moderate earthquakes and interseismic coupling models (fig. 1b), the fault is divided into 4 patches (fig. 2):

1. A deeper rate-strengthening zone, below the seismogenic zone, at downdip distance larger than $160 \mathrm{~km}$ from the trench (or depth larger than $40 \mathrm{~km})$;

2. A seismogenic zone located at 80 to $160 \mathrm{~km}$ from the trench (15 to $40 \mathrm{~km}$ depth) where historical Mw 7.5 earthquakes have occurred;

3. A shallower patch prone to thermal pressurization to get enhanced slip in which we will explore the dependency on the rate and state parameter $(a-b)$; and

4. An updip rate-strengthening patch where coseismic slip tapers off and postseismic slip is observed.

The models do not account for the free surface. We extend the up-dip and down-dip rate-strengthening zones by $40 \mathrm{~km}$, to avoid edge effects on the cumulated slip.

From a mechanical analysis of the forearc deformation, Cubas et al. [2013] found an increase of the static friction coefficient from the inner wedge corresponding to the deeper seismogenic zone to the outer wedge where the maximum of slip occurred. We therefore increase the reference friction coefficient from $\mu_{1}=\mu_{2}=0.6$ in patches 1 and 2 to $\mu_{3}=0.7$ in patch 3 . The friction coefficient is then decreased to $\mu_{4}=0.4$ approaching the trench to simulate under-consolidated clay-rich sediments along the plate interface (Table 1). The effective normal stress can be written as:

$$
\sigma^{e f f}=(1-\lambda) \sigma_{n}
$$

where $\lambda$ is the ratio between the fluid pore pressure and the lithostatic stress. This fluid pore pressure ratio has been shown to be larger than 0.8 along the frontal part of the forearc [Cubas et al., 2013]. Assuming a $\lambda$ of 0.84 , we thus set $\sigma^{\text {eff }}=15 \mathrm{MPa}$ at the trench location, and increase it linearly with depth to $40 \mathrm{MPa}$ at the distance of $50 \mathrm{~km}$ from the trench [Suppe, 2014].

Obtaining rare Tohoku-Oki-like earthquakes requires avoiding the systematic propagation of $\mathrm{Mw} 7.5$ earthquakes to the seafloor. To accomplish that, we explore models that have efficient thermal pressurization only in 


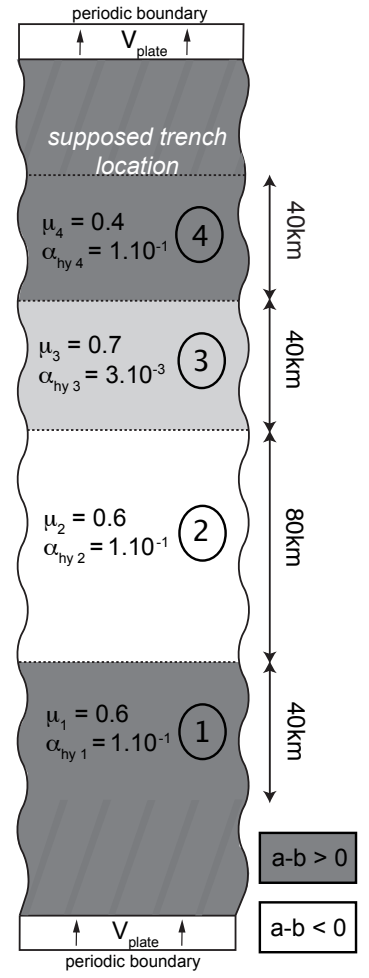

Figure 2: Model set-up. Patch 3 has a higher reference friction coefficient consistent with the study of Cubas et al. (2013) and lower hydraulic diffusivity to get efficient thermal pressurization and enhanced slip. Different values of parameter $(a-b)$ are explored along this patch.

the relatively shallow patch 3 , and not in patch 2 designed to host the observed Mw 7.5 earthquakes. The efficiency of thermal pressurization can be estimated through the characteristic slip $L^{*}$ [Rice, 2006]:

$$
L^{*}=\frac{4}{\mu_{0}^{2}}\left(\frac{\rho_{c}}{\Lambda}\right)^{2} \frac{\left(\sqrt{\alpha}_{h y}+\sqrt{\alpha}_{t h}\right)^{2}}{V} .
$$

Slip comparable to $L^{*}$ induces substantial thermal pressurization, and hence substantial weakening, in a model where slip is confined to a mathematical plane. In this study, following Noda and Lapusta [2010], we distribute the slip over a narrow but finite shear zone while computing the temperature evolution (Eqs. 4-6), and hence $L^{*}$ is an approximation useful in the order-ofmagnitude sense. Since hydraulic diffusivity $\alpha_{h y}$ is typically much larger than 
the thermal diffusivity $\alpha_{t h}, L^{*}$ is approximately proportional to $\alpha_{h y}$, which varies by orders of magnitude in laboratory studies of fault samples [Tanikawa and Shimamoto, 2009]. To get thermal pressurization only in patch 3, we use relatively small hydraulic diffusivity there (Table 1) and larger values elsewhere, with all values within laboratory measurements of Tanikawa and Shimamoto [2009]. In the shallowest patch 4, the larger hydraulic diffusivity simulates unconsolidated clays close to the trench. Even in patch 3, the chosen parameters lead to $L^{*}=18 \mathrm{~m}$, enabling only relatively large slips of the order of $10 \mathrm{~m}$ to activate efficient weakening.

All other parameters are constrained to their commonly used values [Noda and Lapusta, 2010; 2013; Table 1]. We simulate fault slip over thousands of years using the spectral boundary integral approach [Lapusta et al., 2000; Lapusta and Liu, 2009; Noda and Lapusta, 2010]. Following the criteria described in Lapusta and Liu [2009], the 280-km-long megathrust is discretized into 40-m cells.

Table 1: Mechanical and hydraulic properties used in dynamic simulations.

\begin{tabular}{lll} 
& Symbol & Value \\
\hline Shear modulus & $G$ & $30 \mathrm{GPa}$ \\
Poisson's ratio & $\nu$ & 0.25 \\
Shear wave speed & $c_{s}$ & $3 \mathrm{~km} / \mathrm{s}$ \\
\hline Plate velocity & $V_{\text {plate }}$ & $8.5 \mathrm{~cm} / \mathrm{yr}$ \\
Reference slip rate & $V_{0}$ & $10^{-6} \mathrm{~m} / \mathrm{s}$ \\
Characteristic slip distance & $L$ & $0.004 \mathrm{~m}$ \\
Parameter $a$ & $a$ & 0.01 \\
Static friction, patches 1 and 2 & $\mu_{1}, \mu_{2}$ & 0.6 \\
Static friction, patch 3 & $\mu_{3}$ & 0.7 \\
Static friction, patch 4 & $\mu_{4}$ & 0.4 \\
\hline Specific heat & $\rho_{c}$ & $2.7 \mathrm{MPa} / \mathrm{K}$ \\
Hydraulic diffusivity, patches 1,2 and 4 & $\alpha_{h y 1}, \alpha_{h y 2}, \alpha_{h y} 4$ & $10^{-1} \mathrm{~m}^{2} / \mathrm{s}$ \\
Hydraulic diffusivity, patch 3 & $\alpha_{h y 3}$ & $3.10^{-3} \mathrm{~m}^{2} / \mathrm{s}$ \\
Thermal diffusivity & $\alpha_{t h}$ & $10^{-6} \mathrm{~m}^{2} / \mathrm{s}$ \\
Undrained $\Delta p / \Delta T$ & $\Lambda$ & $0.1 \mathrm{M} \mathrm{Pa}^{-\mathrm{K}}$ \\
Half width of shear zone & $h_{w}$ & $10^{-2} \mathrm{~m}$ \\
\hline
\end{tabular}




\section{Results}

\subsection{Dependence of the model behavior on parameter $(a-b)$}

We explore the dependence of the model behavior on the value of $(a-b)$ of patch 3 (Table 2), considering several typical rate-strengthening values, from 0.004 to 0.011 (Models A1-A4), the rate-neutral case $(a-b=0.0$; Model B) and finally a rate-weakening value $(a-b=-0.004$; Model C1). 


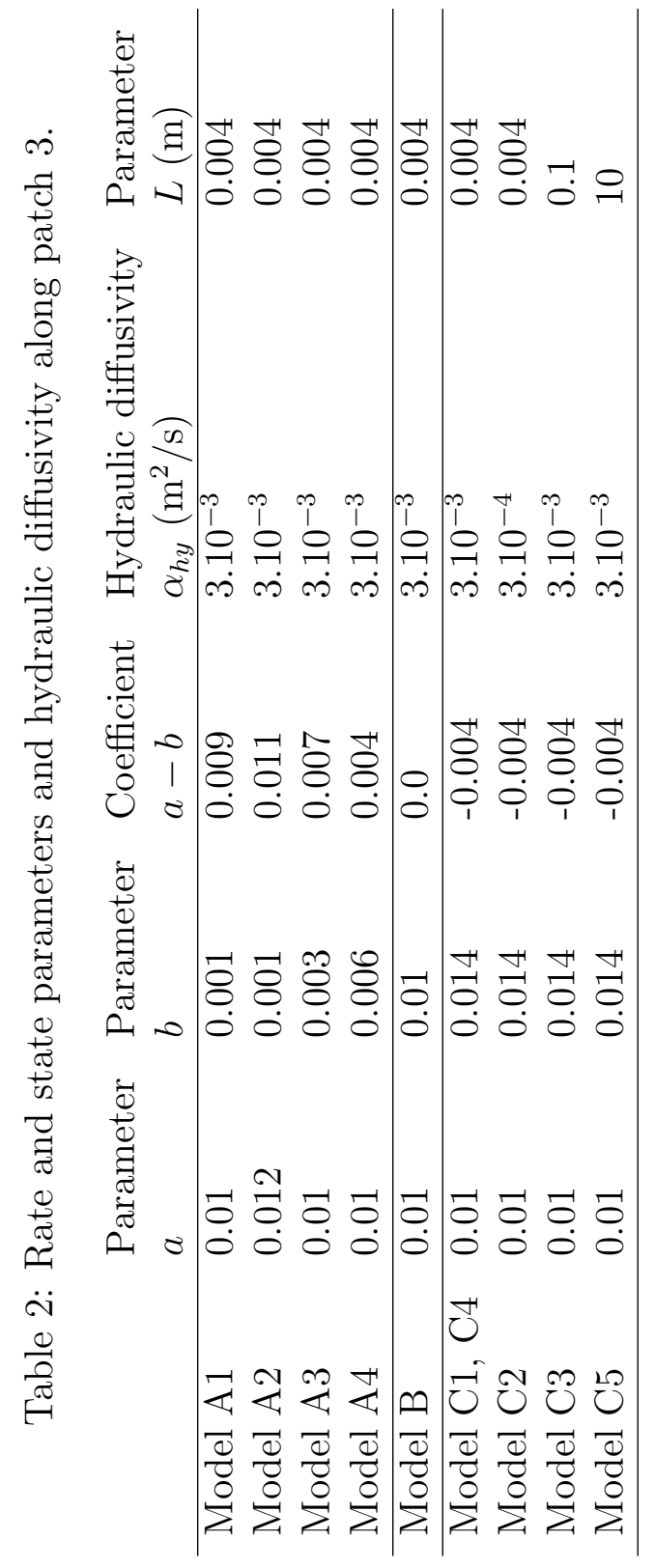


All models reproduce some of the Fukushima-Miyagi segment characteristics (fig. 3 and 4): the alternation between deeper moderate events and much larger events with large slip along patch 3 , as well as the shallow postseismic slip. We refer to these much larger events as 'large' events in the following. Since the simulations are 2D, we cannot determine the exact magnitude of these earthquakes. According to their slip (typically of the order of meters) and the along-dip extent of the ruptures (about $80 \mathrm{~km}$ ), the moderate earthquakes correspond to a magnitude ranging from 7 to 8 .

There are, however, important differences between the response of the models. The first one is in the recurrence time of large events. In Models A1-A4 and, to some extent, in Model B, interseismic slip takes place up-dip, including in patch 3 which is rate-strengthening at low slip rates, increasing the recurrence time of large events. Since no interseismic slip can occur along most of the shallow rate-weakening patch 3 in model $\mathrm{C} 1(a-b=$ $-0.004)$, the recurrence time of large events in that model is determined by the amount of co-seismic slip. In the presented example, the recurrence time is relatively short, ranging between 200 and 250 years. The smaller recurrence time of larger events leads to smaller number of moderate events. Some of them rupture patch 3, in contradiction with the observed historical seismicity along the Fukushima-Miyagi segment which is confined to patch 2. As expected, the recurrence time increases with larger, rate-strengthening $(a-b)$ (figures 3-4): from three hundred years in Model A4 $(a-b=0.004)$ to about four hundred years in Model A3 $(a-b=0.007)$, to a thousand years in Model A1 $(a-b=0.009)$, and more than two thousand years in Model A2 $(a-b=0.011)$. As a consequence, the number of Mw-7.5-like earthquakes observed between large events as well as their magnitude increase with larger recurrence time.

So, clearly, making patch 3 more rate-strengthening increases the recurrence time of large events, allowing the model to match the inferred recurrence time of about a thousand years for the Japan megathrust. Another way to increase the recurrence time for a model with a rate-weakening patch, such as Model C1, is to have larger co-seismic slip in patch 3. This larger co-seismic slip can be achieved with a more efficient shear-induced weakening along patch 3 . To explore this avenue, we decrease the hydraulic diffusivity in patch 3 of Model C1 by one order of magnitude (Model C2, $\alpha_{h y}=3.10^{-4} \mathrm{~m}^{2} / \mathrm{s}$; figure $5 \mathrm{a}$ ). This change leads to the decrease of $L^{*}$ from $18 \mathrm{~m}$ to $2 \mathrm{~m}$, facilitating more slip during large events. Indeed, the recurrence time increases from 200 years to 300 years (figure 5a). To increase the re- 

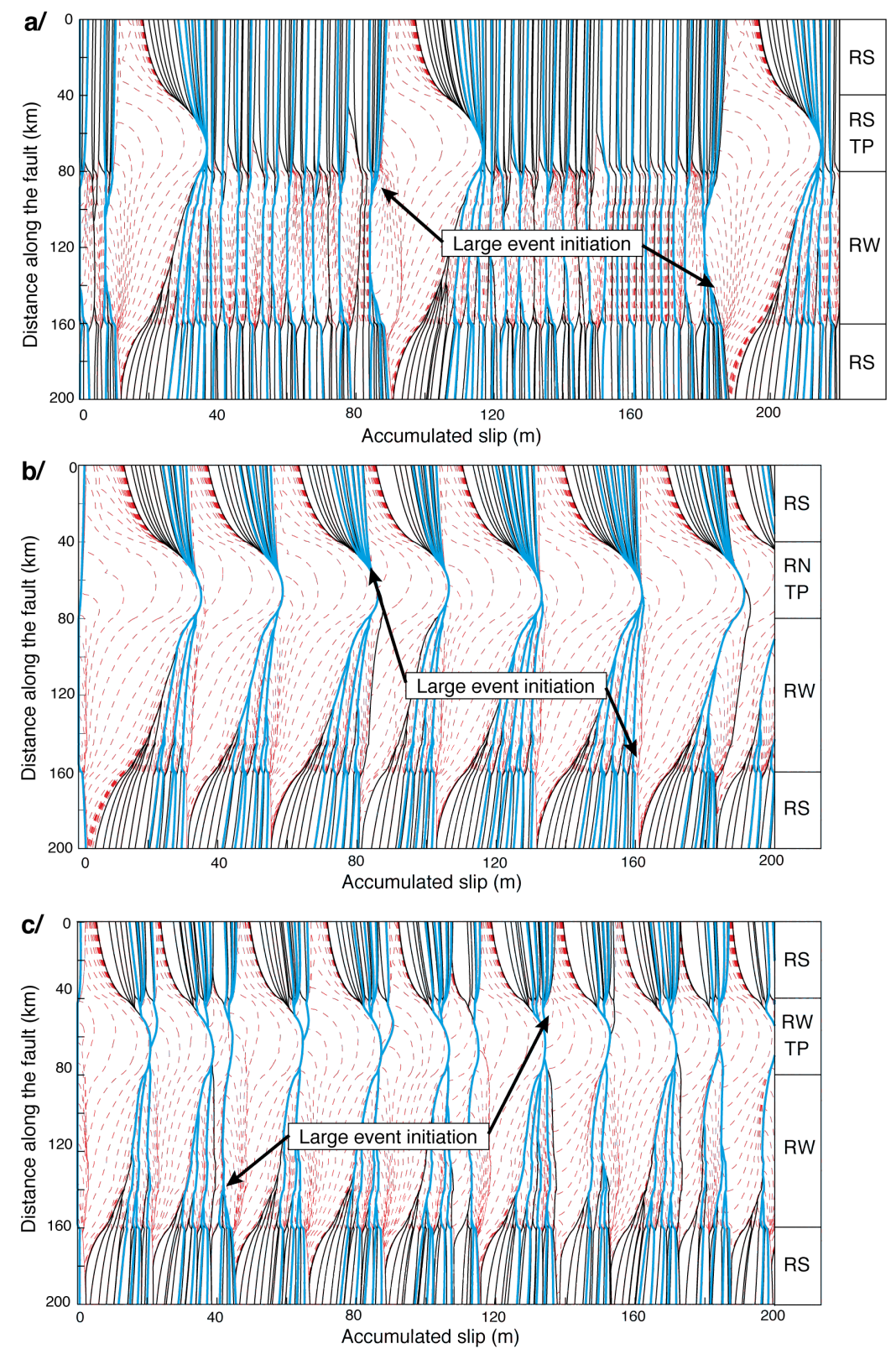

Figure 3: Accumulated slip as a function of the distance along the fault, for a/ Model A1, rate-strengthening patch $3(a-b=0.009)$; b/ Model B, rate-neutral patch $3(a-b=0.0)$; c/ Model $\mathrm{C} 1$, rate-weakening patch 3 $(a-b=-0.004)$. Dashed red lines show coseismic slip every 4 seconds, thick blue lines indicate interseismic slip every 50 years, thin black lines signify the end of each earthquake. Here and in similar Figures, zero slip corresponds to fault slip after several tens of simulated earthquakes, to focus on the longterm response of the model. 

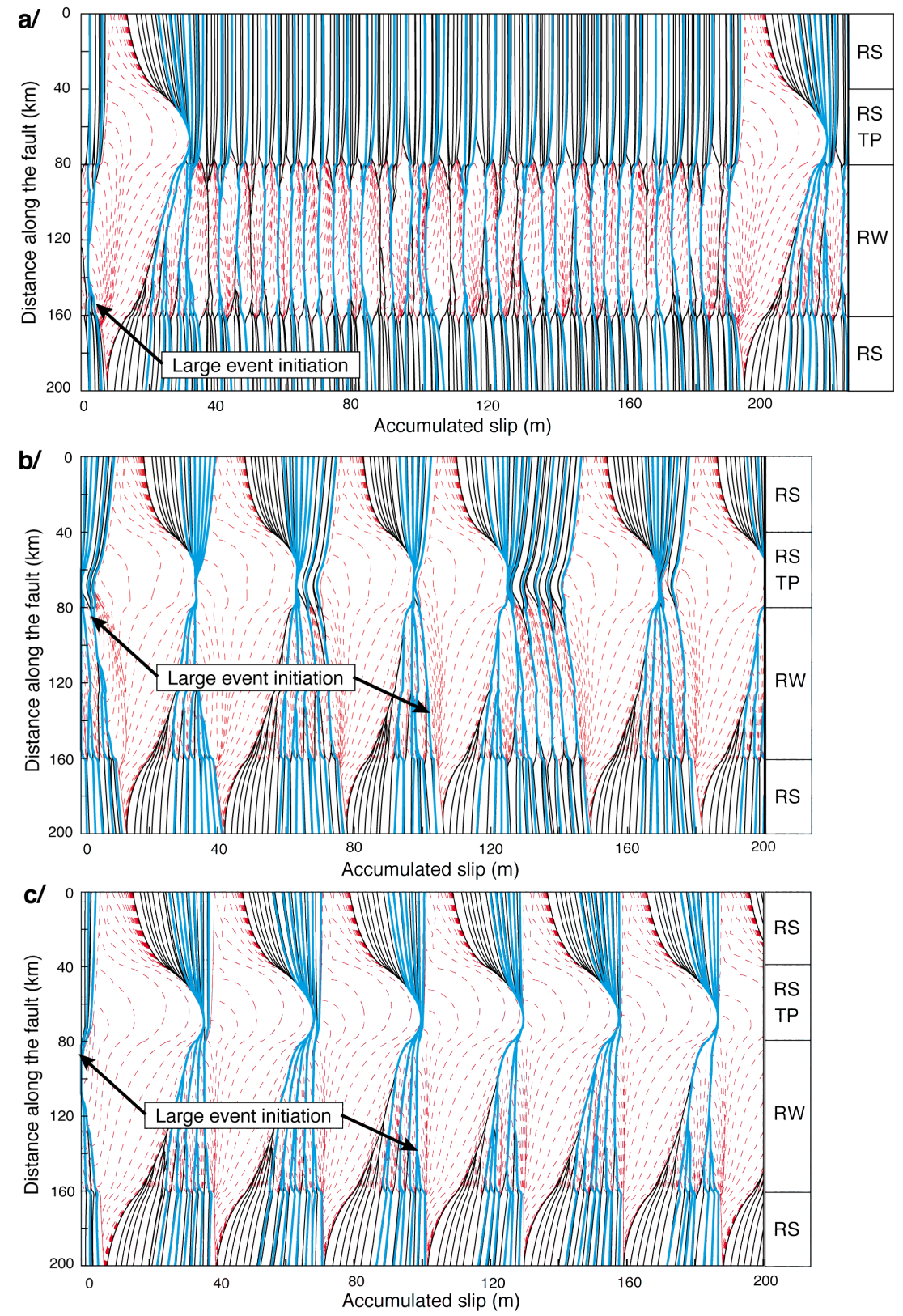

Figure 4: Accumulated slip as a function of the distance along the fault with rate-strengthening patch 3 for different $a-b$ values: a/ Model A2 $(a-b=$ $0.011)$; b/ Model A3 $(a-b=0.007) ; \mathrm{c} /$ Model A4 $(a-b=0.004)$. Dashed red lines show coseismic slip every 4 seconds, thick blue lines indicate interseismic slip every 50 years, thin black lines signify the end of each earthquake. 
currence time in a model with rate-weakening patch 3 to a thousand years, a much larger co-seismic slip in patch 3 , of 80 to $90 \mathrm{~m}$ would be required throughout patch 3; however, such large co-seismic slip over a large fault area is inconsistent with observations.

Yet another way to increase the recurrence time of large events would be to increase the nucleation size of earthquakes over patch 3 . This can

be achieved either by decreasing the effective normal stress or by increasing parameter $L$. The increase of nucleation size could also lead to transient slow slip events. However, the decrease of the effective normal stress would result in a small shear stress drop and would not produce large shallow slip. We thus test the effect of an increase of parameter $L$.

\subsection{Effect of an increase of the nucleation size}

Earthquakes can develop in a rate-weakening patch only if the size of the patch exceeds the nucleation size [e.g., Rice and Ruina, 1983; Rice, 1993; Rubin and Ampuero, 2005]. One theoretical estimate of the earthquake nucleation size, $h_{R R}^{*}$, was derived by Rice and Ruina [1983] using the linear stability analysis of steady sliding:

$$
h_{R R}^{*}=\frac{\pi}{4} \frac{G /(1-\nu) L}{(b-a) \sigma} .
$$

Another one is from Rubin and Ampuero [2005], $h_{R A}^{*}$, derived for the parameter regime $(a / b)>0.5$ using the energy balance for a quasi-statically extending crack:

$$
h_{R A}^{*}=\frac{2}{\pi} \frac{G /(1-\nu) b L}{(b-a)^{2} \sigma} .
$$

For Model C3 (table 2), we choose $L=0.1 \mathrm{~m}$ in order to get a nucleation size comparable to the size of patch $3\left(h_{R R}^{*}=24.5 \mathrm{~km}, h_{R A}^{*}=69.6 \mathrm{~km}\right)$. We observe the same alternation between deeper moderate events and large events with large slip along patch 3 , as well as the shallow postseismic slip (fig. 6a). After large events, patch 3 is first locked and then creeps aseismically. The recurrence time of large earthquakes is increased in comparison to Model C1, to about 430 years. Larger values of $L$ lead to more interseismic creep in patch 3 between large events and a longer recurrence interval, about 545 years for $L=10 \mathrm{~m}$ (fig. 6b). This is understandable, since increasing values 

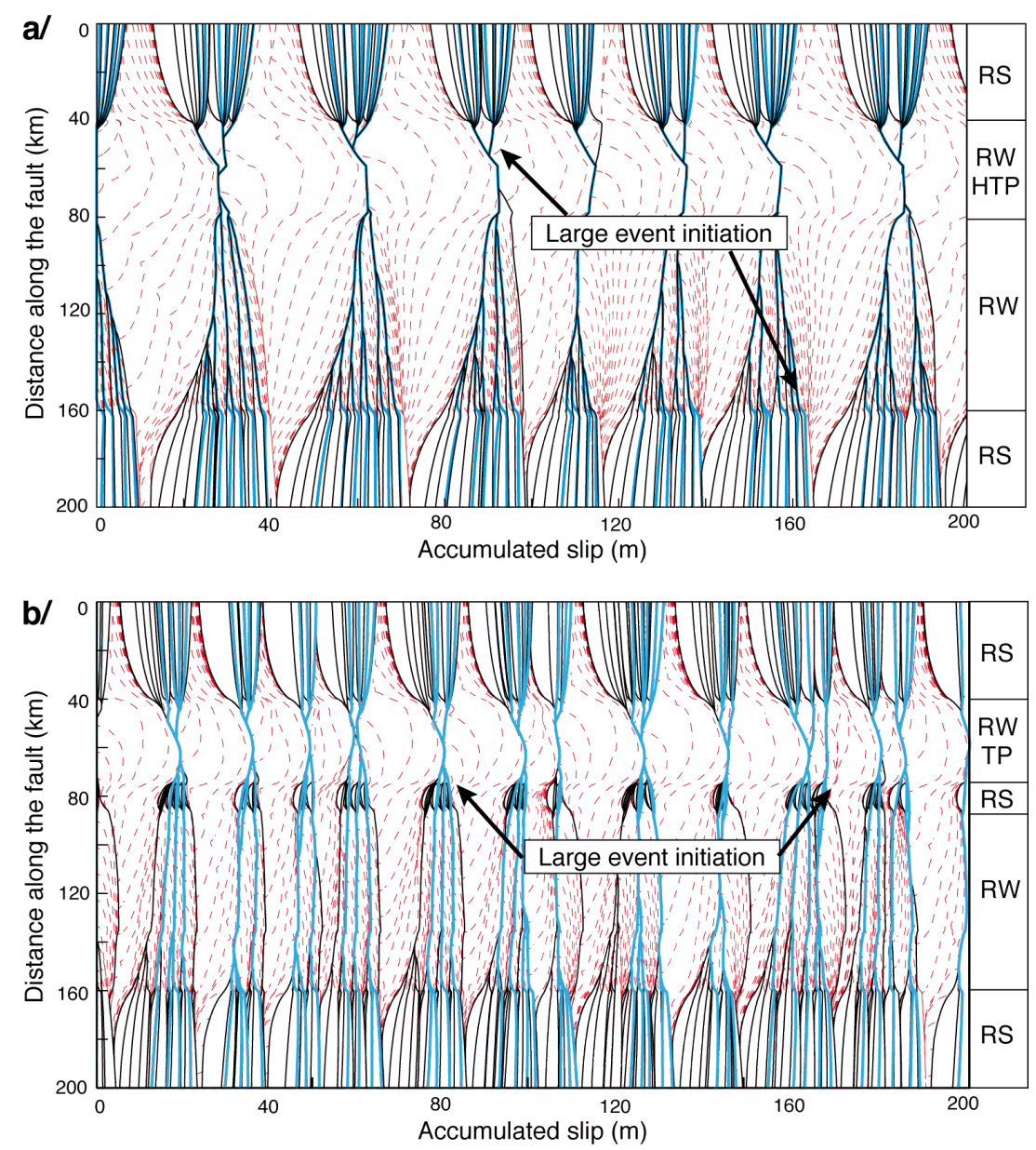

Figure 5: Accumulated slip as a function of the distance along the fault for a/ Model C2, with rate-weakening patch 3 prone to more efficient shear-heating-induced weakening than Model C1 and b/ Model C4 with a rate-strengthening barrier of $10 \mathrm{~km}$ between patch 2 and 3 . The ratestrengthening barrier has the same static friction $\mu$ and hydraulic diffusivity $\alpha_{\text {hy }}$ as patch 2. Dashed red lines show coseismic slip every 4 seconds, thick blue lines indicate interseismic slip every 50 years, thin black lines signify the end of each earthquake. 
of $L$ lead to increasingly stable slip on the patch; if $L$ were infinite, the patch would behave as a velocity-strengthening one with the effective $(a-b)$ given by $a(0.01$ in this model). Note that even $L=10 \mathrm{~m}$ does not allow us to match the thousand-year recurrence times as observed, and such large values of $L$ do not have any experimental support.

\subsection{Effect of a rate-strengthening barrier between two rate-weakening patches}

To potentially avoid moderate events rupturing both patches 2 and 3 as well as decrease the number of large events of Model C1, we also explore the effect of a rate-strengthening barrier between patches 2 and 3 (fig. 5b). In Model C4, a $10 \mathrm{~km}$ barrier has been added with the same reference friction coefficient and hydraulic diffusivity as in patch 2 and $(a-b)=0.009$. A similar recurrence time for large events is obtained (in comparison with Model $\mathrm{C} 1$ ), although moderate events extending over both patches 2 and 3 become more limited. However, all large earthquakes nucleate in the shallow rateweakening patch, which also hosts some small events. This is because it is easier to propagate through the barrier from patch 3, which has much larger slip due to dynamic weakening, than from patch 2. In Model C4, once the event nucleates close to the middle of the fault in patch 3 , it readily propagates up because of dynamic weakening but its propagation down is delayed by the presence of the barrier. We do not observe backward propagation. The same conclusion should hold for stronger barriers (the ones with either larger values of the velocity-strengthening parameter $(a-b)$ or large sizes), and hence simulations with stronger barriers would also have largest events that start in patch 3 and propagate into patch 2, contrary to the observations of Ide et al. [2011]. For strong enough patches, the events that span both patches 2 and 3 will disappear altogether. On the contrary, weaker barriers (the ones with either less velocity strengthening or smaller sizes) would induce more events over patches 2 and 3 .

\subsection{Large events characteristics}

We now compare characteristics of large events in models with a velocitystrengthening (Model A1) and velocity-weakening (Model C4) patch 3 with the 2011 Tohoku-Oki earthquake. First, the slip distribution with depth is approximately reproduced in both models. An exact comparison of the slip 

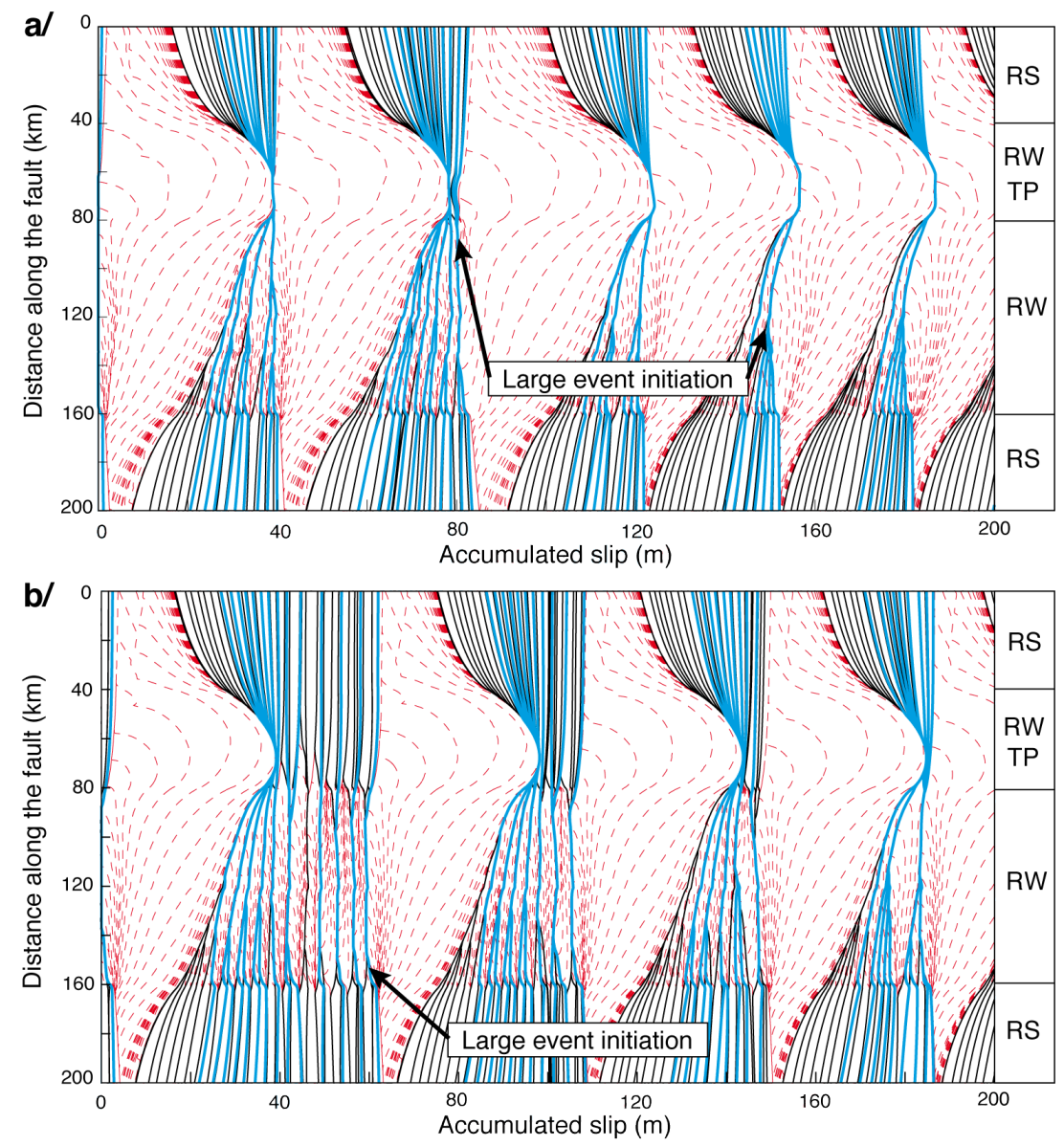

Figure 6: Accumulated slip as a function of the distance along the fault for a/ Model C3, with rate-weakening patch 3 with a larger value of $L(0.1 \mathrm{~m})$ resulting in the nucleation size larger than patch, and b/ even larger $L=$ $10 \mathrm{~m}$. Dashed red lines show coseismic slip every 4 seconds, thick blue lines indicate interseismic slip every 50 years, thin black lines signify the end of each earthquake. 
values is not useful since our models are $2 \mathrm{D}$ and hence approximate. Furthermore, the simulated values can be somewhat adjusted by adjustments of the model parameters such as friction coefficient values, hydraulic diffusivity etc.

Next, we examine the frequency content (fig. 7a). For both models, we observe more high frequency radiation along the deeper patch and more low frequency radiation along the shallower patch. This difference is due to the difference in thermal pressurization efficiency as already reported by Noda and Lapusta [2013]. The difference is larger with Model A1, probably because of the enhanced thermal pressurization, and perhaps also due to the initial rate-strengthening response in patch 3 for Model A1. Still, both models reproduce the observation that high frequency waves during the Tohoku-Oki earthquake were dominantly generated by the deeper part of the rupture [Ide et al., 2011; Meng et al., 2011; Wei et al., 2012].

Note that nucleation in the middle of the fault is required to reproduce the rupture pattern of the 2011 Tohoku-Oki earthquake as determined by Ide et al. [2011]. The rupture went down first, then up, then down again, re-rupturing the bottom patch (fig. 7b). This pattern occasionally occurs in Models A1, C1, C2 and C3 but never in Model C4 with a barrier. In Model A1, earthquakes cannot nucleate in the rate-strengthening patch 3, and hence all events nucleate in the deeper rate-weakening patch 2 . Once in a while, an event penetrates into the rate-strengthening patch 3 energetically enough to activate shear-heating-induced weakening there through pore fluid pressurization, in which case a large event results. If a large event nucleates at the transition between the shallow rate-strengthening and rate-weakening patches, the timing of the rupture propagation observed during the TohokuOki earthquake is quite well reproduced in Model A1 (fig. 7c). The rupture first propagates for $38 \mathrm{~s}$ downdip, then exhibits extensive shallow slip between 40 and $75 \mathrm{~s}$, and then re-ruptures the downdip megathrust up to $100 \mathrm{~s}$, very similar to what has been observed by Ide et al. [2011] for the Tohoku-Oki event.

Another intriguing particularity is observed with Model A1: supershear speeds are reached by the rupture front along the shallow rate-strengthening patch. Such behavior was also observed by Kaneko and Lapusta [2010] for a model with linear slip-weakening friction close to the free surface. In both cases, the behavior is likely due to low effective normal and shear stresses close to the free surface, which make the stress perturbations coming with waves from the deeper portions of the fault significant enough to transition 
al
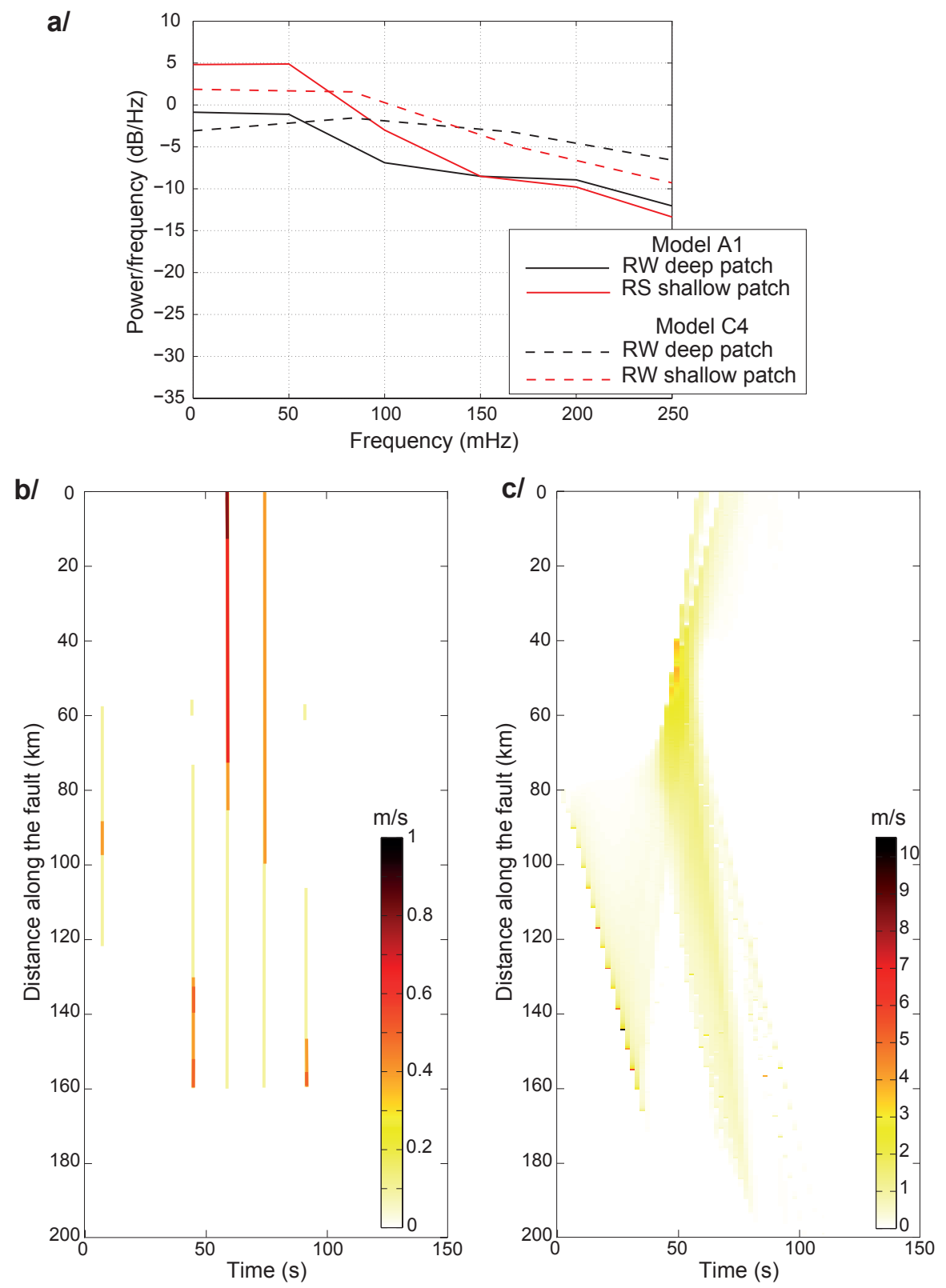

Figure 7: a/ Comparison of Welch Power Spectral Density Estimate [Welch, 1967] of the slip rate for the deeper and shallower patches of models C4 and A1 for a representative large event. Slip rate as a function of time and distance from the trench b/ from the work of Ide et al. [2011] for the 2011 Tohoku-Oki event, c/ from model A1, when a large earthquake nucleates at the rate-strengthening/rate-weakening transition as in fig. 3a (slip rate is plotted every $2 \mathrm{~s})$. 
the rupture to supershear.

Note that high, above-melting temperatures are reached at the deeper rate-weakening patch in our models during large events. The models can be improved by either incorporating the effects of melting, which could involve a combination of weakening and strengthening of the fault [Tsutsumi and Shimamoto, 1997; Di Toro et al., 2006], or modifying the friction properties so that the melting temperatures are not reached. In the latter case, the reference friction coefficient or the effective normal stress need to be reduced. Co-seismic weakening, e.g. efficient thermal pressurization, can also be incorporated in that region, although, without other changes, that would lead to larger slips there, potentially contrary to observation, especially during the re-rupturing of those portions of the fault.

\section{Discussion - Conclusion}

This study shows that fault models with rate-and-state friction that incorporate enhanced co-seismic weakening due to thermal pressurization at a distance of 40 to $80 \mathrm{~km}$ from the trench reproduce several inferred features of the 2011 Tohoku-Oki earthquake as well as the overall fault behavior in the region. Such models reproduce an observed alternation between several deeper moderate $(\mathrm{M} \sim 7.5)$ events and much larger $(\mathrm{M} \sim 9)$ events that accumulate significant slip close to the trench. The models also reproduce dominant high-frequency radiation from the deeper portions of the fault as well as the complex up- and down-dip rupture propagation inferred for the 2011 event. These features are reproduced regardless of whether the shallower portions of the fault (between 40 and $80 \mathrm{~km}$ in our models) have rate-strengthening or rate-weakening friction properties at low slip rates.

The comparison of our models with the inferred $\sim 1000$-year recurrence of the largest events as well as the seismic behavior over the last 300 years favors a rate-strengthening friction of the shallower patch at low slip rates. The rate-strengthening properties result in interseismic creep in addition to occasional significant co-seismic slip, allowing the model to reproduce the inferred recurrence times of the order of 1000 years. We are not able to reproduce such a long recurrence time in any other model, including ones with a barrier. The rate-strengthening properties near the trench also explain the lack of smaller seismicity near the trench in the last 300 years (except for the rare large events), as observed along the Japan megathrust as well as 
along most subduction megathrusts worldwide [Byrne et al., 1992].

With a rate-weakening shallow patch, (1) the recurrence time of large events is smaller than the one inferred from tsunami records and (2) moderate events could rupture both patches 2 and 3, in contradiction with the observed location of $\mathrm{Mw} 7$ to 8 earthquakes along the Fukushima-Miyagi segment. A barrier between the two rate-weakening patches results in nucleation from the shallow patch for large events, in contradiction with the observations. A more efficient thermal pressurization or a larger value of $L$ can increase the recurrence time but without reaching the 1000 years deduced from tsunami records. Models with large values of parameter $L$ (such as C3) produce more shallow slip, variation of coupling during the interseismic period as proposed by Sato et al. (2013), and possible slow slip events. However, the model does not reproduce the observed recurrence time for the values of $L$ as high as 10 $\mathrm{m}$, and such large values do not have much laboratory or theoretical support.

The efficient thermal pressurization is obtained along the shallow portion of the megathrust by a local increase of static friction and decrease of the hydraulic diffusivity. The increase of static friction is consistent with values retrieved by Cubas et al. [2013]. In addition, the work of Cubas et al. [2013] found a long-term low effective friction as well as a dynamic increase of the pore pressure along the high slip patch, both consistent with a locally low permeability leading to more efficient thermal pressurization. This local variation in permeability could be related to the low incoming sediment thickness or the disrupted oceanic crust by horst and grabben.

The main limitation of our models is their much simplified geometry. First, our models do not truly account for the free surface, although they do incorporate an increase of the stresses with depth which is one of the features due to the free surface. The true free surface would further promote slip along the high slip patch and at the surface [e.g., Kozdon and Dunham, 2013]. Since the shallow coseismic and postseismic slips produced by our simulations are lower than those retrieved from the observations, such enhanced slip at the surface would actually bring our simulations closer to the observations. Second, our model considers a planar 1-D fault embedded into a 2-D elastic medium, whereas the megathrust has a complex 3D shape and, in particular, it is curved next to the trench. The important advantage of our simulations is their ability to consider long slip histories and faithfully reproduce the interaction of seismic and aseismic slip. It would be important to verify the conclusions of this study in fully 3D simulations of a non-planar megathrust with a true free surface, although we anticipate that the results would be 
qualitatively similar. However, such simulations of long slip histories are not feasible at present.

Overall, our study shows that the features of the great 2011 Tohoku-Oki earthquake as well as historic observations in the area are consistent with the traditional picture of rate-strengthening (and mostly aseismic) shallow portions of megathrusts, with the caveat of their potential co-seismic weakening during extreme events. When such 'stable' areas do weaken co-seismically, they have the potential to accumulate large seismic slips due to nearly complete stress drops. Hence it is important to assess the potential and consequences of such rare but catastrophic events on other fault segments that are currently considered to be stable (i.e., creeping or decoupled).

\section{Acknowledgment}

We thank our two reviewers, Roland Brgmann and Sylvain Barbot, for their constructive comments. We thanks Olivier Lengliné for helpfull discussion. This project was supported by the National Science Foundation through EAR grants 1118239 and 1142183 and by the Gordon and Betty Moore Foundation through grant GBMF \#423.01 to the Caltech Tectonics Observatory. This is Tectonics Observatory contribution \#280.

\section{References}

Barbot, Sylvain, N. Lapusta, and J. P. Avouac (2012), Under the Hood of the Earthquake Machine: Toward Predictive Modeling of the Seismic Cycle, Science, v.336, p.707-710, doi:10.1126/science.1218796.

Bletery, Q., A. Sladen, B. Delouis, M. Vallé, J.-M. Nocquet, L. Rolland, and J. Jiang (2014), A detailed source model for the Mw 9.0 Tohoku-Oki earthquake reconciling geodesy, seismology, and tsunami records, $J$. Geophys. Res., v.119, doi:10.1002/2014JB011261.

Bürgmann R., M. G. Kogan, G. M. Steblov, G. Hilley, V. E. Levin, and E. Apel (2005), Interseismic coupling and asperity distribution along the Kamchatka subduction zone, J. Geophys. Res., v.110, B07405, doi:10.1029/2005JB003648.

Byrne, D. E., L. R. Sykes, and D. M. Davis (1992), Great thrust earth- 
quakes and aseismic slip along the plate boundary of the Makran subduction zone, J. Geophys. Res., 97, B1, p.449-478,DOI: 10.1029/91JB02165

Cubas, N., J. P. Avouac, Y. M. Leroy, and A. Pons (2013), Low friction along the high slip patch of the 2011 Mw 9.0 Tohoku-Oki earthquake required from the wedge structure and extensional splay faults, Geophys. Res. Lett., v. 40, doi:10.1002/grl.50682.

Dieterich, J. H. (1979), modeling of rock friction: 1. Experimental results and constitutive equations, J. Geophys. Res., v. 84, p.2161-2168, doi:10.1029/JB084iB05p02161.

Di Toro G., T. Hirose, S. Nielsen, G. Pennacchioni, T. Shimamoto (2006), Natural and Experimental Evidence of Melt Lubrication of Faults During Earthquakes, Science, v.311, 5761, p.647-649, doi: 10.1126/science.1121012.

Faulkner, D. R., T. M. Mitchell, J. Behnsen, T. Hirose, and T. Shimamoto (2011), Stuck in the mud? Earthquake nucleation and propagation through accretionary forearcs, Geophys. Res. Lett., v.38, L18303, doi:10.1029/2011GL048552.

Fujiwara, T., S. Kodaira, T. No, Y. Kaiho, N. Takahashi, and Y. Kaneda (2011), The 2011 Tohoku-Oki earthquake: Displacement reaching the trench axis., Science, v.334, 1240, doi:10.1126/science.1211554.

Fulton, P. M., E. E. Brodsky, Y. Kano, J. J. Mori, F. M. Chester, T. Ishikawa, R. N. Harris, W. Lin, N. Egnuchi, S. Toczko and Expedition 343, 343T and KR13-08 Scientists (2013), Low coseismic friction on the Tohoku-Oki Fault determined from temperature measurements, Science, DOI: $10.1126 /$ science.1243641.

Hashimoto, C., A. Noda, T. Sagiya and M. Matsu?ura (2009), Interplate seismogenic zones along the Kuril-Japan trench inferred from GPS data inversion, Nature Geosci., v.2, p.141-144,DOI: 10.1038/ngeo421.

Hetland, E.A., and M. Simons (2010), Postseismic and interseismic deformation due to fault creep II: Transient creep and interseismic stress shadows on megathrusts, Geophys. J. Int., 181, 99-112, doi:10.1111/j.1365246X.2009.04482.x.

Hu Y., R. Bürgmann, J. T. Freymueller, P. Banerjee and K. Wang (2014), Contributions of poroelastic rebound and a weak volcanic arc to the postseismic deformation of the 2011 Tohoku earthquake, Earth, Planets and Space, 66:106, doi:10.1186/1880-5981-66-106.

Ide, S., A. Baltay and G.C. Beroza (2011), Shallow dynamic overshoot and energetic deep rupture in the $2011 \mathrm{Mw} 9.0$ Tohoku-oki earthquake, 
Science, v.332, p.1426-1429, doi:10.1126/science.1207020.

Ito, Y., T. Tsuji, Y. Osada, M. Kido, D. Inazu, Y. Hayashi, H. Tsushima, R. Hino and H. Fujimoto (2011), Frontal wedge deformation near the source region of the 2011 Tohoku-oki earthquake, Geophys. Res. Lett., v.38, doi:10.1029/2011GL048355.

Johnson, K. M., J. Fukuda, and P. Segall (2012), Challenging the rate-state asperity model: Afterslip following the 2011 M9 Tohoku-oki, Japan, earthquake, Geophys. Res. Lett., v.39, doi:10.1029/2012GL052901. Kaneko, Y., and N. Lapusta (2010), Supershear transition due to a free surface in 3-D simulations of spontaneous dynamic rupture on vertical strike-slip faults, Tectonophysics, doi: 10.1016/j.tecto.2010.06.015.

Kozdon, J. E. and E. M. Dunham (2013), Rupture to the trench: Dynamic rupture simulations of the 11 March 2011 Tohoku earthquake, Bulletin of the Seismological Society of America, 103(2B), p.1275-1289, doi:10.1785/0120120136.

Lachenbruch, A.H. (1980), Frictional heating, fluid pressure, and the resistance to fault motion, J. Geophys. Res., v. 85, p.6097-6112, doi: 10.1029/JB085iB11p06097.

Lapusta, N., J. R. Rice, Y. Ben-Zion, and G. Zheng (2000), Elastodynamic analysis for slow tectonic loading with spontaneous rupture episodes on faults with rate- and state-dependent friction, J. Geophys. Res., v.105, 23,765-23,789, doi:10.1029/2000JB900250.

Lapusta, N., and Y. Liu (2009), Three-dimensional boundary integral modeling of spontaneous earthquake sequences and aseismic slip, $J$. Geophys. Res., v.114, B09303, doi:10.1029/2008JB005934.

Loveless, J.P. and B.J. Meade (2011), Spatial correlation of interseismic coupling and coseismic rupture Extent of the $2011 \mathrm{Mw}$ 9.0 Tohoku-oki earthquake, Geophys. Res. Lett., v.38, L17306, doi:10.1029/2011GL048561.

Mase, C.W., and Smith, L. (1985), Pore-fluid pressures and frictional heating on a fault surface, Pure and Applied Geophysics, v. 122, p.583-607, doi: 10.1007/BF00874618.

Mase, C.W., and Smith, L. (1987), Effects of frictional heating on the thermal, hydrologic, and mechanical response of a fault, J. Geophys. Res., v. 92, no. B7, p.6249-6272, doi: 10.1029/JB092iB07p06249.

Matsumoto, Y., T. Ishikawa, M. Fujita, M. Sato, H. Saito, M. Mochizuki, T. Yabuki, and A. Asada (2008), Weak interplate coupling beneath the subduction zone of Fukushima, NE Japan, inferred from GPS/acoustic 
seaoor geodetic observation, Earth Planets Space, 60.

Meng, L., A. Inbal, and J.-P. Ampuero (2011), A window into the complexity of the dynamic rupture of the $2011 \mathrm{Mw} 9$ Tohoku-Oki earthquake, Geophys. Res. Lett., 38, L00G07, doi:10.1029/2011GL048118.

Mitsu, Y., Y. Iio, and Y. Fukahata (2012), A scenario for the generation process of the 2011 Tohoku earthquake based on dynamic rupture simulation: role of stress concentration and thermal fluid pressurization, Earth Planets Space, 64, p.1177-1187, doi:10.5047/eps.2012.05.016.

Noda, H., and N. Lapusta (2010), Three-dimensional earthquake sequence simulations with evolving temperature and pore pressure due to shear heating: Effect of heterogeneous hydraulic diffusivity, J. Geophys. Res., v.115, B12314, doi:10.1029/2010JB007780.

Noda, H. and N. Lapusta (2013), Stable creeping fault segments can become destructive as a result of dynamic weakening, Nature, v.493, p.518-521, doi:10.1038/nature11703.

Oglesby, D. D., R. J. Archuleta, and S. B. Nielsen (1998), Earthquakes on dipping faults: The effects of broken symmetry, Science, 280(5366), p.1055-1059, DOI: 10.1126/science.280.5366.1055.

Oleskevich, D.A., R.D. Hyndman and K. Wang (1999), The updip and downdip limits to great subduction earthquakes: thermal and structural models of Cascadia, south Alaska, SW Japan, and Chile, J. of Geophys. Res., v.104, p.14,965-14,991, doi:10.1029/1999JB900060.

Ozawa, S., T. Nishimura, H. Suito, T. Kobayashi, M. Tobita and T. Imakiire (2011), Coseismic and postseismic slip of the 2011 magnitude 9 TohokuOki earthquake, Nature, v.117, p.373-376, doi:10.1038/nature10227.

Ozawa, S., T. Nishimura, H. Munekata, H. Suito, T. Kobayashi, M. Tobita, and T. Imakiire (2012), Preceding, coseismic, and postseismic slips of the 2011 Tohoku earthquake, J. of Geophys. Res., 117, doi:10.1029/2011JB009120.

Perfettini and Avouac, (2014), The Seismic Cycle in the Area of the 2011 Mw9:0 Tohoku-Oki Earthquake, J. Geophys. Res., 119, doi:10.1002/2013JB010697.

Rice, J.R. (2006), Heating and weakening of faults during earthquake slip, J. Geophys. Res., v. 111, B05311, doi: 10.1029/2005JB004006.

Rice, J. R. (1993), Spatio-temporal complexity of slip on a fault, $J$. Geophys. Res., 98, 9885-9907, doi:10.1029/93JB00191.

Rice, J. R., and A. L. Ruina (1983), Stability of steady frictional slipping, J. Appl. Mech., v.50, p.343-349. 
Rubin, A. M., and J.-P. Ampuero (2005), Earthquake nucleation on (aging) rate and state faults, J. Geophys. Res., 110, B11312, doi:10.1029/2005JB003686.

Ruina, A. L. (1983), Slip instabilities and state variable friction laws, J. Geophys. Res., v.88, 10,359-10,370, doi:10.1029/JB088iB12p10359.

Sato, M., M. Fujita, Y. Matsumoto, T. Ishikawa, H. Saito, M. Mochizuki, and A. Asada (2013), Interplate coupling off northeastern Japan before the 2011 Tohoku-oki earthquake, inferred from seafloor geodetic data, $J$. Geophys. Res. Solid Earth, v.118, 3860-3869, doi:10.1002/jgrb.50275.

Sawai, Y., Y. Namegaya, Y. Okamura, K. Satake, and M. Shishikura (2012), Challenges of anticipating the 2011 Tohoku earthquake and tsunami using coastal geology, Geophys. Res. Lett., v.39, L21309, doi:10.1029/2012GL053692.

Shibazaki, B., T. Matsuzawa, A. Tsutsumi, K. Ujiie, A. Hasegawa, and Y. Ito (2011), 3D modeling of the cycle of a great Tohoku-oki earthquake, considering frictional behavior at low to high slip velocities, Geophys. Res. Lett., v.38, L21305, doi:10.1029/2011GL049308.

Sibson, R.H. (1973), Interaction between temperature and pore-fluid pressure during earthquake faulting - A mechanism for partial or total stress relief, Nature, v. 243, p.66-68.

Simons, M., S.E. Minson, A. Sladen, F. Ortega, J.L. Jiang, S.E. Owen, L.S. Meng, J.P. Ampuero, S.J. Wei, R.S Chu, D.V. Helmberger, H. Kanamori, E. Hetland, A.W. Moore and F.H. Webb (2011), The 2011 magnitude 9.0 Tohoku-Oki earthquake: mosaicking the megathrust from seconds to centuries, Science, v.332, p.1421-1425, DOI: 10.1126/science.1206731.

Sun, T., K. Wang, T. Iinuma, R. Hino, J. He, H. Fujimoto, M. Kido, Y. Osada, Satoshi M., Y. Ohta and Y. Hu (2014), Prevalence of viscoelastic relaxation after the 2011 Tohoku-oki earthquake, Nature, 514, p.84-87, doi:10.1038/nature13778.

Suppe, J. (2014), Fluid overpressures and strength of the sedimentary upper crust, J. of Structural Geology, v.69, p.481-492, doi:10.1016/j.jsg.2014.07.009.

Tanikawa, W. and T. Shimamoto (2009), Frictional and transport properties of the Chelungpu fault from shallow borehole data and their correlation with seismic behavior during the 1999 Chi-Chi earthquake, J. Geophys. Res., v.114, B01502, DOI: 10.1029/2008JB005750.

Tsutsumi A. andT. Shimamoto (1997), High-velocity frictional 
properties of gabbro, Geophys. Res. Lett., v.24, 6, p.699-702, doi: 10.1029/97GL00503.

Yamanaka, Y., and M. Kikuchi (2004), Asperity map along the subduction zone in northeastern Japan inferred from regional seismic data, $J$. Geophys. Res., 109, B07307, doi:10.1029/2003JB002683.

Yamagiwa, S., S. Miyazaki, K. Hirahara, and Y. Fukahata (2015), Afterslip and viscoelastic relaxation following the 2011 Tohoku-oki earthquake (Mw9.0) inferred from inland GPS and seafloor GPS/Acoustic data, Geophys. Res. Lett., 42, doi:10.1002/2014GL061735.

Watanabe, S., M. Sato, M. Fujita, T. Ishikawa, Y. Yokota, N. Ujihara, and A. Asada (2014), Evidence of viscoelastic deformation following the 2011 Tohoku-Oki earthquake revealed from seafloor geodetic observation, Geophys. Res. Lett., 41, 57895796, doi:10.1002/2014GL061134.

Wei, S., R. Graves, D. Helmberger, J.P. Avouac and J. Jiang (2012), Sources of shaking and flooding during the Tohoku-Oki earthquake: A mixture of rupture styles, Earth and Planet. Sci. Lett., v.333-334, p.91-100, doi:10.1016/j.epsl.2012.04.006.

Welch, P.D. (1967), The Use of Fast Fourier Transform for the Estimation of Power Spectra: A Method Based on Time Averaging Over Short, Modified Periodogram, IEEE Transactions on Audio Electroacoustics, AU-15, 7073. 